\title{
Antigo Testamento Interlinear Hebraico-Português: Profetas Posteriores (volume 3) Breve Apresentação e Descrição
}

Edson de Faria Francisco

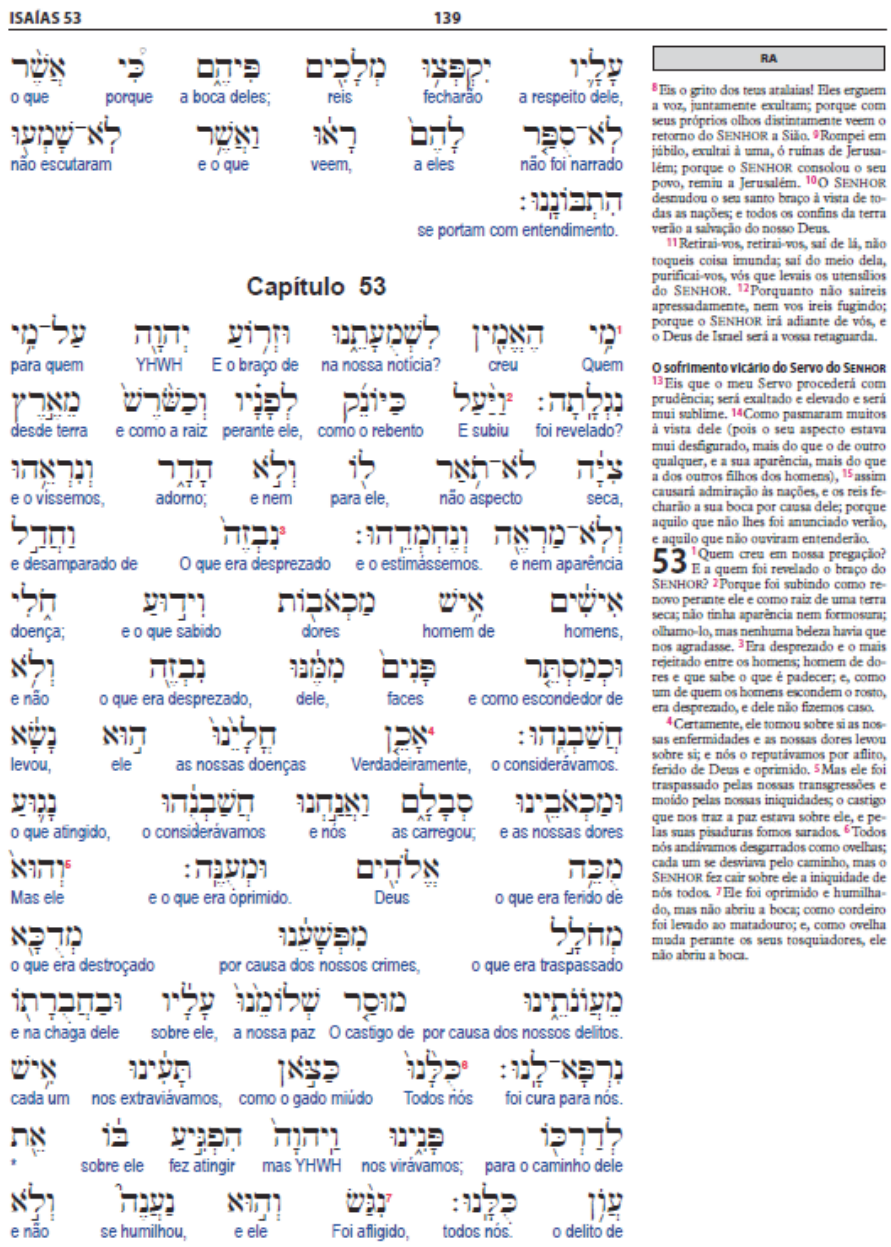

Figura 1: Página do Antigo Testamento Interlinear Hebraico-Português, vol. 3: Profetas Posteriores, Isaías $52.15 \mathrm{a}-53.7 \mathrm{a}, \mathrm{p} .139$. 


\title{
RESUMO
}

Breve apresentação e descrição do Antigo Testamento Interlinear Hebraico-Português: Profetas Posteriores (volume 3), publicado pela Sociedade Bíblica do Brasil.

\begin{abstract}
Short presentation and description of the Antigo Testamento Interlinear Hebraico-Português: Profetas Posteriores (volume 3) [Old Testament Interlinear Hebrew-Portuguese: Latter Prophets (volume 3)], published by Brazilian Bible Society.

RESUMEN

Breve presentación y descripción del Antigo Testamento Interlinear Hebraico-Português, vol. 3: Profetas Posteriores, publicado por la Sociedad Bíblica de Brasil.
\end{abstract}

Em novembro de 2017, foi publicada, pela Sociedade Bíblica do Brasil (SBB), a obra Antigo Testamento Interlinear Hebraico-Português (ATI): Profetas Posteriores (volume 3). Como os dois primeiros volumes, a nova publicação é uma edição interlinear, apresentando tradução literal do texto original hebraico e aramaico da Bíblia Hebraica (Antigo Testamento) para o português. Tal característica é um dos principais e mais importantes destaques da referida edição publicada pela SBB. O projeto tem o apoio da Universidade Metodista de São Paulo (UMESP), sendo desenvolvido pelo professor Edson de Faria Francisco. Portanto, a nova edição pode ser considerada mais uma importante contribuição da UMESP, por meio da Faculdade de Teologia da Igreja Metodista (FaTeo), para todas as sociedades que são falantes da língua portuguesa.

No ATI, procurou-se traduzir, literalmente, cada palavra e cada expressão da Bíblia Hebraica para o português, seguindo o seu sentido original. Cada palavra ou expressão em português segue passo-a-passo cada palavra e expressão do texto original hebraico, da direita para a esquerda. Na primeira linha, consta o texto hebraico e, na linha logo abaixo, consta a tradução literal em português (cf. Figura 1).

Como nos dois primeiros volumes, que são dedicados ao Pentateuco (Sociedade Bíblica do Brasil - SBB, 2012) e aos Profetas Anteriores (SBB, 2014), no ATI são apresentados, além do texto original da Bíblia Hebraica e uma tradução literal correspondente em português, a A Bíblia Sagrada - Versão Revista e Atualizada (RA), tradução de João Ferreira de Almeida (SBB, 1993) e a Bíblia Sagrada - Nova Tradução na Linguagem de Hoje (NTLH) (SBB, 2000). No ATI, adotou-se o mesmo projeto editorial adotado no Novo Testamento Interlinear Grego-Português (2004), também publicado pela SBB.

$\mathrm{O}$ terceiro tomo do $A T I$, que segue a sequência do cânon judaico, tendo por base a Biblia Hebraica Stuttgartensia (BHS) (Deutsche Bibelgesellschaft, 1997), abrange os seguintes escritos bíblicos: Isaías, Jeremias, Ezequiel e os Doze (Oseias, Joel, Amós, Abdias, Jonas, Miqueias, Naum, Habacuque, 
Sofonias, Ageu, Zacarias e Malaquias). Este volume, assim como os dois primeiros, possui um capítulo intitulado "Dificuldades Textuais", no qual são comentados os principais problemas de tradução encontrados ao longo do processo de elaboração do terceiro volume do ATI. Duas informações importantes sobre o tomo atual:

1. Após os três livros maiores de Isaías, Jeremias e Ezequiel, consta o livro dos Doze Profetas. A tradição judaica considera tal bloco de livros como um único livro.

2. Lamentações não consta após Jeremias e Daniel não consta após Ezequiel. Esses dois livros bíblicos aparecerão apenas no quarto volume do ATI, que conterá os Escritos: Salmos, Jó, Provérbios, Rute, Cântico dos Cânticos, Eclesiastes, Lamentações, Ester, Daniel, Esdras-Neemias, 1Crônicas e 2Crônicas.

Determinados trechos e livros bíblicos foram muito difíceis de serem vertidos, requerendo profundo cuidado no processo de tradução. As principais passagens e livros que apresentam alto grau de dificuldade de tradução são: Os 1.1-14.10 (o livro inteiro), Mq 1.1-7.20 (o livro inteiro), Hc 2.6-20 (os cinco ais contra os caldeus), Hc 3.1-19 (a oração de Habacuque) e Sf 1.1-3.20 (o livro inteiro). Tais textos apresentam diversos fenômenos linguísticos peculiares: palavras e expressões únicas (isto é, aquelas que aparecem uma única vez em todo o texto da Bíblia Hebraica), vocabulário de baixa utilização, utilização gramatical insólita, redação inusitada e possíveis situações de corrupção textual, em que o texto não está bem conservado. O ATI traduz tais textos de acordo com a sua natureza gramatical, mesmo que em português a tradução soe, no geral, muito estranha e, às vezes, sem sentido algum. Contudo, a tradução de tais trechos que se encontra no ATI reflete, o mais próximo possível, o que se acha, realmente, no texto original hebraico. Além de tais trechos, outros também foram de tradução dificílima: Ez 1.1-28 (a visão da carruagem de YHWH), Ez 10.1-17 (a visão dos carvões ardentes de fogo e a visão das quatro rodas) e Ez 40.1-42.20 (a edificação do futuro templo de Jerusalém). Nos dois primeiros textos, constata-se que há uso gramatical inesperado, como troca ilógica de sufixos pronominais masculinos por femininos e vice-versa, troca de pronomes demonstrativos no plural por pronomes demonstrativos no singular, entre outras situações de ordem gramatical. No terceiro e último texto constam vários termos técnicos arquitetônicos de significação desconhecida, o que representou verdadeiro desafio de tradução. Os dicionários de hebraico bíblico, que foram utilizados na produção do $A T I$, não auxiliaram de maneira satisfatória na definição dos vários itens arquitetônicos. Normalmente, são encontradas definições 
genéricas como: "termo técnico arquitetônico desconhecido", "termo técnico arquitetônico de significado incompreensível" e "termo técnico arquitetônico inexplicável". A escolha das acepções para o ATI foi baseada nas obras dicionarísticas de datação mais recente, quando fornecem alguma definição, mesmo que seja mera conjectura.

No atual tomo, em termos de comparação, o livro bíblico de tradução mais fácil foi o de Jonas e o livro bíblico de tradução mais difícil foi o de Miqueias. O primeiro, porque se constata que a redação é muito regular e sem sobressaltos, e o segundo, porque se verifica que há muitos trechos de redação truncada e geralmente a compreensão do texto é, na maior parte das vezes, ininteligível.

Muitas situações de dificuldade de tradução são comentadas no terceiro tomo do ATI, no capítulo intitulado "Dificuldades Textuais" (cf. Figura 2). São explanadas, ao todo, 111 situações de dificuldades textuais encontradas ao longo dos Profetas Posteriores. No referido capítulo, as palavras e expressões de difícil tradução do texto bíblico hebraico são comparadas com três versões bíblicas clássicas: a Septuaginta (versão grega), a Vulgata (versão latina) e o Targum de Jônatas ben Uziel (versão aramaica dos Profetas). Tal atitude restringiu-se a circunstâncias em que o texto hebraico apresentava profundas dificuldades relacionadas com a crítica textual, e as antigas versões poderiam auxiliar na solução do problema. Em algumas ocasiões, consultou-se, ainda, o aparato crítico da BHS, da Biblia Hebraica (BHK) (Württembergische Bibelanstalt, 1973), da Biblia Hebraica Quinta (BHQ), Fascicle 13: The Twelve Minor Prophets (Deutsche Bibelgesellschaft, 2010) e do The Hebrew University Bible (HUB): The Book of Isaiah (1995), The Book of Jeremiah (1997) e de The Book of Ezekiel (2004).

No terceiro tomo do $A T I$, no capítulo "Dificuldades Textuais", são mencionadas pela primeira vez as variantes textuais encontradas nos manuscritos bíblicos descobertos nas onze cavernas de Qumran. Tais informações são baseadas na obra The Biblical Qumran Scrolls: Transcriptions and Textual Variants, editada por Eugene Ulrich (2010), que reúne todos os manuscritos bíblicos, tanto inteiros quanto fragmentários, que foram encontrados no mencionado sítio arqueológico. Além disso, há citações de várias anotações massoréticas colhidas dos códices de Leningrado B19a (L) e de Alepo (A) e também do tratado 'Okhlah we-'Okhlah. Para os dois códices massoréticos mencionados, foram utilizadas edições fac-símiles: a obra The Leningrad Codex: A Facsimile Edition, editada por David N. Freedman et alii (1998) e a obra The Aleppo Codex: Provided with Massoretic Notes and Pointed by Aaron ben Asher - The Codex Considered Authoritative by Maimonides, editada por Moshe H. Goshen- 
Jeremias 25.26 e 51.41

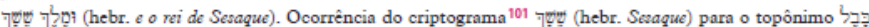
(hebr. a Babilônia) que ocorre duas vezes no livro de Jeremias: Jr 25.26 e $51.41 .{ }^{102}$ Essa situação é o resultado da regra de atbash ${ }^{103}$, isto é, o criptograma Sevaque, que é constituido por três letras, alude à Babilônia. ${ }^{104}$ Abaiso, há a posição numérica de cada uma das trêo letras do criptograma em oentido sequencial e a eua alusão em sentido antioeequencial:

\begin{tabular}{|c|c|c|c|}
\hline \multicolumn{4}{|c|}{ Tשֶׁ(hebr. Sesaque) } \\
\hline letras: & 7 & $v$ & $\boldsymbol{\theta}$ \\
\hline $\begin{array}{l}\text { pooição numérica alfabética } \\
\text { (da letra } \mathrm{K} \text { à letra } \Omega \text { ): }\end{array}$ & $11^{a}$ & $21^{a}$ & $21^{a}$ \\
\hline
\end{tabular}

\begin{tabular}{|l|c|c|c|}
\hline \multicolumn{4}{|c|}{ (ḥִִ (hebr. a Babilonia) } \\
\hline letras: & $\zeta$ & $\beth$ & $21^{2}$ \\
\hline $\begin{array}{l}\text { posição numérica alfabética } \\
\text { (da letra n à letra א): }\end{array}$ & $11^{2}$ & $21^{2}$ & \\
\hline
\end{tabular}

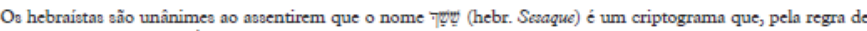

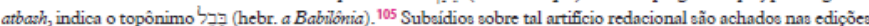
acadêmicas da Bỉblia Hebraica: no bloco inferior do aparato crítico da BHKé achada a oeguinte anotação: $>0$ r, add (o trecho está ausente tanto na Septuaginta quanto na Vetus Latina, o segmento é uma adição); no aparato crítico da

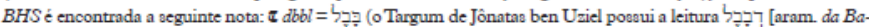
bilônia], que correoponde, por retroveroão, ao topônimo רִִ̣ [hebr. $a$ Babilônia]) e no bloco IV do aparato crítico da HUB constam anotações massoréticas registradas em dois códices sobre o referido criptograma e que são citadas $\mathrm{em}$ Jeremias 25.26: פ (na masora parva do Códice P é regiotrada a seguinte nota: o nome Sesaque indica a Babilônia na gematria) e e (na masora magna do Códice C é encontrada a oeguinte anotação: o nome Seeaque indica a Babilônia na gematria, que é reoultado da regra do atbash). Na masora magna do Códice A em Jeremias 51.41 consta a seguinte nota sobre o meamo assunto: ששך לב קמי כשדים בנימשרייה

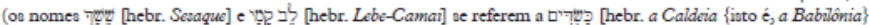
pela gematria [isto $\dot{e}$, a regra de atbash]). As duas referências biblicas dadas na nota mavoorética são: Jr 51.1 e 41.106

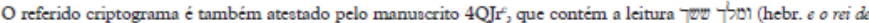

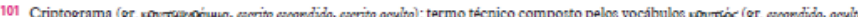
e pósyra (gr. letra, everito). Mensagem ou documento em linguagem cifrada, criptografada, cf. Houaiss eVillar, 2009, p. 573.

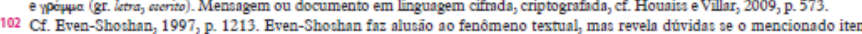

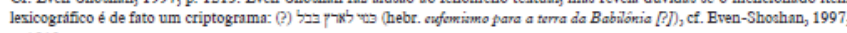
p. 1213.

103 A regra de atbash é um tipo de criptograma em que uma determinada palavra era compoata pela substituiçảo da primeira letra

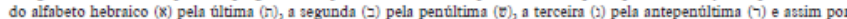
diante. A regra de atbash é também conhecida como gematria. Tal recurso redacional era utilizado para manter determinados nomes ou palavras de maneira criptografada, por algum motivo, para serem decifrados com o passar do tempo. O termo técnico atbosh é uma forma mnemônica que se refere às seguintes letras hebraicas: $x, n, z$ e $v$. Normalmente, a unidade terminológica atbash é escrita de maneira mnemônica como va n nx ou como varnk, cf. Brown, Driver e Briggs, 1996, p. 1058; Jastrow, 2005, p. 131 e 239; Even-Shoshan, 1997 , p. 586 e Francisco, 2008 , p. 25 , n. 3.

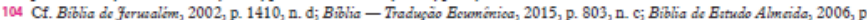
821, n. vi Brown, Driver e Briggs, 1996, p. 1058; Koehler e Baumgartner, 2001, p. 1666 e Jastrow, 2005, p. 131 e 239.

105 Cf. Kirst et alii, 2014, p. 262; Holladay, 2010, p. 243; Alonso Schökel, 2004, p. 795; Brown, Driver e Briggs, 1996, p. 1058; Koehler e Baumgartner, 2001, p. 1666 e Clines, 2009, p. 481

106 Cf. Loewinger, 1977 , p. 134.

Figura 2: Página do Antigo Testamento Interlinear Hebraico-Português, vol. 3: Profetas Posteriores,

"Dificuldades Textuais", p. xxxv.

-Gottstein (1976). Para o citado tratado massorético, foram usadas as obras Das Buch Ochlah W'ochlah (Massora), editada por Salomon Frensdorff (1972), Sefer 'Oklah wě-'Oklah, editada por Fernando Díaz Esteban (1975), La seconda parte del Sefer 'Oklah we-'Oklah, editada por Bruno Ognibeni (1995) e Les listes marginales de la 'oklah de Halle, editada pelo mesmo autor (Sefarad 57, 1997, p. 97-126; 333-371).

Outro detalhe que merece menção no atual volume do ATI são as situações das denominadas tiqqûnê sôferîm (hebr. "correções dos escribas"). Tais correções ou emendas teriam sido efetuadas pelos antigos escribas judeus 
no primitivo texto bíblico hebraico, totalizando, de acordo com a tradição massorética, 18 correções. O motivo de tais correções está relacionado com alguma ofensa a Deus, isto é, quando o texto bíblico parece ofensivo a Deus e que deveria ter algum tipo de alteração. $\mathrm{O}$ trecho com a correção é mantido no próprio texto do $A T I$ e o mesmo trecho, mas sem a correção, é comentado no capítulo "Dificuldades Textuais". Algumas das ocorrências das tiqqûnê sôferîm são citadas e comentadas no citado capítulo. Os casos são constatados nas seguintes passagens dos Profetas Posteriores: Jr 2.11; Ez 8.17; Os 4.7; Hc 1.12; Zc 2.12 e Ml 1.13. Abaixo, estão os seis trechos do texto bíblico sem e com as tiqqûnê sôferim:

\begin{tabular}{|c|c|c|}
\hline texto & trecho sem as tiqqûnế sôferîm & trecho com as tiqqûnế sôferîm \\
\hline Jr 2.11 & a minha glória & a glória dele \\
\hline Ez 8.17 & ao meu nariz & ao nariz deles \\
\hline Os 4.7 & a minha glória & a glória deles \\
\hline Hc 1.12 & não morrerás & não morreremos \\
\hline Zc 2.12 & o meu olho & o olho dele \\
\hline Ml 1.13 & me & a ele \\
\hline
\end{tabular}

Como exemplo, no capítulo "Dificuldades Textuais" há uma descrição geral sobre a redação do livro de Oseias:

Texto de redação muito complexa, com inúmeras situações de hapax legomena (são 163 ocorrências entre hápax parciais e hápax absolutos, de acordo com a masora parva do Códice L), com pouquíssimos casos de ketîv e qerê (são apenas 5 ocorrências: Os 6.10; 8.12 [2 vezes]; 9.16 e 10.10), além de tradução difićlima. Ao longo do livro, constam muitos problemas de ordem gramatical e inúmeras dificuldades de ordem textual [...] Os versículos 4.11; 4.18; 5.2; 5.11; 6.5b; 7.4; 7.6; 7.12b; 8.6; 8.7b; 8.9a; 8.10b; 8.12; 9.2b; 9.3b; 9.13; 10.7; 10.9; 11.7; 12.1b e 13.9 são, particularmente, de redação muito intrincada. Os versos 4.17; 6.9; 7.5 e 10.5 , entre outros, são simplesmente ininteligíveis. Constata-se que várias passagens ao longo da obra estão truncadas, como os versículos $4.5 ; 4.15 ; 7.3 ; 7.11 ; 8.13$ e 9.6. As diversas versões bíblicas em português apresentam variadas interpretações do texto, por causa da problemática textual e gramatical que se verifica ao longo do livro bíblico.

Tal descrição, mesmo que geral, fornece ao leitor uma ideia, mesmo que superficial, sobre o estado redacional do citado livro bíblico.

O ATI apresenta tradução calcada no texto original hebraico de tradição massorética, possuindo acepções novas que diferem das demais edições bíblicas em língua portuguesa. As definições são baseadas em vários dicionários de hebraico bíblico, principalmente naqueles que são considerados clássicos. Alguns exemplos entre a $R A$ e a NTLH, por um lado, e o $A T I$, por outro, são dados a seguir: 


\begin{tabular}{|c|c|c|}
\hline texto & $R A$ e $N T L H$ & $A T I$ \\
\hline Is 1.21 & $\begin{array}{l}\text { visão de Isaías,/ } \\
\text { as mensagens... a Isaías, }\end{array}$ & a palavra de revelação de Isaías, \\
\hline Is 2.1 & $\begin{array}{c}\text { palavra que,..., veio a lsaías, } \\
\text { a mensagem... a Isaías, }\end{array}$ & a palavra que enxergou Isaías, \\
\hline Is 7.11 & $\begin{array}{c}\text { nas profundezas, } \\
\text { das profundezas do mundo dos }\end{array}$ & para o sheol, \\
\hline Is 7.14 & $\begin{array}{l}\text { a virgem conceberá/ } \\
\text { a jovem que está grávida }\end{array}$ & a mulher jovem grávida, \\
\hline Is 9.6 & $\begin{array}{l}\text { SENHOR dos Exércitos/ } \\
\text { SENHOR Todo-Poderoso }\end{array}$ & YHWH Tsevaote \\
\hline Jr 1.5 & $\begin{array}{l}\text { profeta às nações/ } \\
\text { um profeta para as nações }\end{array}$ & anunciador para as nações \\
\hline Jr 16.14 & $\begin{array}{c}\text { diz o SENHOR,/ } \\
\text { o SENHOR Deus diz: }\end{array}$ & o enunciado de YHWH; \\
\hline Ez 16.15 & $\begin{array}{c}\text { e te ofereceste/ } \\
\text { para dormir com qualquer um }\end{array}$ & $\begin{array}{l}\text { os teus procedimentos } \\
\text { prostituídos }\end{array}$ \\
\hline Os 5.13 & ao rei principal/do poderoso rei & para grande rei \\
\hline$J 11.4$ & $\begin{array}{c}\text { gafanhoto cortador,... gafanhoto } \\
\text { migrador,... gafanhoto devora- } \\
\text { dor,... gafanhoto destruidor/ } \\
\text { nuvens e mais nuvens de gafa- } \\
\text { nhotos }\end{array}$ & $\begin{array}{c}\text { locusta larva,... locusta } \\
\text { migratória,... locusta serpeante,... } \\
\text { locusta devoradora }\end{array}$ \\
\hline Jn 4.6 & uma planta/uma planta & rícino \\
\hline Na 3.6 & imundícias/sujeira & objetos sacros repugnantes \\
\hline Zc 9.7 & abominações/comida impura & alimentos sacros repugnantes \\
\hline
\end{tabular}

Espera-se que o terceiro tomo do ATI, apresentado e descrito de maneira muito sucinta neste texto, possa ser importante contribuição do Brasil para os demais países de língua portuguesa e possa ser importante também para a história da tradução da Bíblia em língua portuguesa. Além disso, espera-se que tanto o atual volume do $A T I$ como os dois primeiros sejam úteis para todos que se dedicam à leitura e ao estudo do texto veterotestamentário nas suas línguas originais.

\section{Referências bibliográficas}

Almeida, João Ferreira de (trad.). A Bíblia Sagrada. Versão revista e atualizada. Barueri: Sociedade Bíblica do Brasil, 1993.

Bíblia Sagrada. Nova tradução na linguagem de hoje. Barueri: Sociedade Bíblica do Brasil, 2000. Díaz Esteban, Fernando. Sefer 'Oklah wě-'Oklah - Colección de listas de palabras destinadas a conservar la integridad del texto hebreo de la Biblia entre los judios de la Edad Media. Cardenal Cisneros, vol. 4, 1975. 
FrensdorfF, Salomon (ed.). Das Buch Ochlah W'ochlah (Massora), Herausgegeben, übersetzt und mit erläuternden Anmerkungen versehen nach einer, soweit bekannt, einzigen, in der Kaiserlichen Bibliothek zu Paris befindlichen Handschrift). New York: Ktav, 1972.

Goshen-Gottstein, Moshe H. (ed.). The Hebrew University Bible: the Book of Isaiah. Jerusalem: Magnes Press, 1995.

Goshen-Gottstein, Moshe H.; Talmon, Shemaryahu (eds.). The Hebrew University Bible: the Book of Ezekiel. Jerusalem: Magnes Press, 2004.

Ognibeni, Bruno (ed.). La seconda parte del Sefer 'Oklah we-'Oklah. Edizione del Ms. Halle, Universitätsbibliothek YB 4 10, ff. 68-124. Cardenal Cisneros, Madrid-Fribourg, vol. 57, 1995. 1997. (ed.). Les listes marginales de la 'oklah de Halle. Sefarad 57, p. 97-126; 333-371,

Ulrich, Eugene (ed.). The Biblical Qumran Scrolls: Transcriptions and Textual Variants. Supplements to Vetus Testamentum, Leiden-Boston, vol. 134, 2010. 